\title{
Yapay Zekâ ve Stratejik Yönetim
}

\section{N. Öykü iYiGÜN*}

"Yeni bir fikre açılan zihin, asla orijinal boyutlarına geri dönmez."

Einstein

Günümüzde baş döndürücü hızla yaşanan iletişim ve bilişim teknolojilerindeki büyük değişim ve dönüşüme uyum sağlamaya ve hatta bunları yönetmeye çalışan insanlık, tarihte görülmemiş düzeyde yeni, çok boyutlu ve bilinmeyen konularla karşılaşmaktadır. Bu değişim rüzgârının sadece işletmeler açısından değil; bireyler, toplumlar ve hatta devletler seviyesinde çok ciddi ve hatta yıkıcı etkileri bulunmakta ve tüm aktörleri proaktif davranmaya, hızlı ve yenilikçi çözümler üretmeye ve cesur adımlar atıp stratejiler geliştirmeye zorlamaktadır.

Zihin; yaşantıları, öğrenilenleri, bunların geçmişle olan bağlantılarını bilinçli olarak kavrama ve algılama yetisi olarak ifade edilebilir. Yeni bir fikre açılan zihin, değişmeye başlar ve kaçınılmaz olarak dönüşür. Stratejik yönetim, vizyon oluşturmakla mümkün olabilir. Vizyon ise hayal etmek, en ilham verici noktayı bulmak ve bunu kurumsal düzeyde geleceğe dair planlama ile bağdaştırmak olarak tanımlanabilir. Proaktif olabilmek, hazırlıklı olmak, uzun vadeli planlama yapmak ve stratejik yönetim bakış açısıyla konuları ele almakla ilgilidir. Dolayısıyla stratejik yönetim, Edward Fredkin'in ifade ettiği gibi çığır açıcı düzeyde dönüştürücü olan yapay zekâ gibi bir kavram için oldukça önemlidir. Bu anlamda yapay zekâ başta olmak üzere nesnelerin interneti, büyük veri, makine öğrenimi, derin öğrenme, doğal dil işleme, arttırılmış ve sanal gerçeklik, blockchain ve Mesh Teknolojisi gibi teknolojiler takip edilmesi zorunlu alanlar hâline gelmiştir.

Yapay zekâ, bir makineye algılama, muhakeme etme ve öğrenme gibi bilişsel işlevleri gerçekleştirme yeteneği sağlayan güçlü bir teknoloji olarak ifade edilmektedir (Ergen, 2019). Diğer bir ifadeyle yapay zekâ, makinelerin deneyimden öğrenmesini, yeni girdilere uyum sağlamasını ve insanın yaptğına benzeri görevleri gerçekleştirmesini mümkün kılmaktadır. Bu noktada yapay zekânın, görevleri yerine ge- 
tirmek için insan zekâsını taklit ettiği ve topladıkları bilgilere göre yinelemeli olarak kendilerini iyileştirebilen sistemler veya makineler olduğu söylenebilir. Bilgisayar teknolojilerinde yaşanan gelişmeler yapay zekânın kullanımını hızlandırmış ve yapay zekâ tekniklerinin kullanımı, pek çok endüstriyel problemin çözümünde başarılı sonuçlar vermiştir (Kaya ve Engin, 2005). Yapay zekâ sistem ve uygulamaları; perakendeden hastalıkların teşhisine, üretim sistemlerinden satışa, yabancı dil çevirisinden hizmet sunumuna ve hatta askeri uygulamalara kadar birçok alanda kullanılmakta ve birçok endüstriyi dönüştürmektedir. Bu kadar farklı alanda gitgide fazla kullanılmaya başlanan yapay zekânın geleceğine ilişkin fikirler, bilim insanları ve uzmanlar tarafindan çok çeşitli şekillerde tahmin edilmektedir (Bostrom, 2018).

2010 yılından bu yana, endüstriyel robotlara eklenen teknik yenilikler ile robotlara olan talep önemli ölçüde artmış ve 2014-2019 yılları arasında endüstriyel robotların yıllık kurulum oranı ortalama \%11 artş göstermiştir (IFR, 2020). Otomatikleştirilmiş teknoloji kullanımının gelecek yirmi yıldaki mevcut işlerin neredeyse yarısını değiştirmesi beklenmektedir. Teknolojik devrim olarak adlandırılabilecek bu değişim ve dönüşüm, ekonomi ve iş gücünde yerleşik bulunan düzen, ilke ve teamüllerin temellerini sarsmaktadır (Acemoğlu ve Restrepo, 2019). Bu noktada yeni istihdam düzenlemeleri, teknolojik ilerlemelerin hızı ve değişen iş gücü demografisi; uluslararası örgütleri, ulusal hükümetleri ve özel sektör profesyonellerini mesleklerin geleceğinin bu eğilimlerden nasıl etkileneceği konusunda görüşler sunmaya ve araştırmalar yürütmeye yönlendirmiştir. Kişisel verilerin kullanılması ile ilgili gizlilik sorunları, iş gücü piyasalarındaki teknolojilerin kutuplaşma etkileri ve genişleyen siber saldırılar yapay zekâ sistemleri konusunda öne çıkan başlıca zorluklar olarak ifade edilebilir. Bunlarla beraber, yapay zekânın beraberinde getireceği etik ikilemler, sosyal yaşamın dijital bireylere dönüşümü, haklar ve fikri mülkiyet ile ilgili sorunlar, akıllı sistemlerin yapay zekâ temelli sistemler oluşturması gibi senaryolar da çeşitli araştırmacılar tarafindan tartş̧ımaktadır (Köse, 2018). Ayrıca yapay zekâ devrimi, demokrasi ile otoriterlik arasındaki mevcut değerler çatışmasını daha da şiddetlendirmektedir (Schmidt, 2021). Yapay zekâ gibi gelişmekte olan teknolojiler iş ve mesleklerin geleceği konusundaki raporlarda ve akademik araştırmalarda en çok ilgi çeken konuların başında gelmekte ve yapay zekânın rolünün işletmelerin stratejisinde daha bütünsel hâle geleceği belirtilmektedir (Howard, 2019).

Stratejik yönetim sürecinin en önemli adımlarından bir tanesi strateji oluşturmak ve buna bağlı olarak da stratejik planlama yapmaktır. Bu noktada Cumhurbaşkanıı̆ı Dijital Dönüşüm Ofisi Başkanlığı ile Sanayi ve Teknoloji Bakanlığı tarafindan hazırlanan, Türkiye'nin yapay zekâ çalışmalarına yön verecek ilk "Ulusal Yapay Zekâ 
Stratejisi", 20/08/2021 tarihli ve 31574 sayılı Resmî Gazete'de yayımlanarak yürürlüğe girmiş ve 24 Ağustos 2021 tarihinde Bilişim Vadisi'nde kamuoyu ile paylaşılmıştır.

Ulusal Yapay Zekâ Stratejisi, 2021-2025 yıllarını kapsayacak şekilde oluşturulmuştur. Ulusal Yapay Zekâ Stratejisi, ülkemizin yapay zekâ alanındaki çalışmalarını bütünleştirip ortak bir zemin yaratarak, yönetişim mekanizmaları ortaya koymayı amaçlayan bir strateji belgesi olarak yorumlanabilir. Ulusal Yapay Zekâ Stratejisi ile stratejik öncelikler belirlenmiş ve vizyon oluşturulmuştur. Ulusal Yapay Zekâ Stratejisi'nin vizyonu “Müreffeh bir Türkiye için çevik ve sürdürülebilir yapay zekâ ekosistemiyle küresel ölçekte değer üretmek" olarak belirlenmiştir. Ulusal Yapay Zekâ Stratejisi'nde 6 stratejik öncelik belirlenmiştir (Ulusal Yapay Zekâ Stratejisi, 2021):

- Yapay zekâ uzmanlarını yetiştirmek ve alanda istihdamı artırmak

- Araştırma, girişimcilik ve yenilikçiliği desteklemek

- Kaliteli veriye ve teknik altyapıya erişim imkanlarını genişletmek

- Sosyoekonomik uyumu hızlandıracak düzenlemeleri yapmak

- Uluslararası düzeyde iş birliklerini güçlendirmek

- Yapısal ve iş gücü dönüşümünü hızlandırmak

Ulusal Yapay Zekâ Stratejisi'nin öncelikleri, ülkemizin “Dijital Türkiye” vizyonu ve "Milli Teknoloji Hamlesi" ile uyumlu olacak şekilde kurgulanmıştır. Bu da stratejik yönetim açısından ülkemizin doğru zamanda doğru adımları atabilmek için gerekli hazırlıkları yaptığını ve önceliklerini belirleyerek, strateji oluşturma safhasını tamamladığını göstermektedir. Ancak unutmamak gerekir ki yapay zekâ, alan olarak doğru şekilde ele alınmazsa riskler, faydalarından çok daha ağır basabilir. Facebook CEO'su Mark Zuckerberg gibi teknoloji girişimcileri, yapay zekânın insan hayatını kurtarabileceğini ama aynı zamanda kötüye kullanılabileceğini, bu sebeple de çok dikkatli ve tedbirli olmak gerektiğini savunmaktadır. Öte yandan Tesla ve SpaceX CEO'su Elon Musk ise yapay zekânın muhtemelen insanlığın karşı karşıya kaldığı en büyük varoluşsal tehditlerden biri olduğunu öne sürmüş ve düzenleyicilerin proaktif olmaları gerektiğini savunmaktadır (İyigün, 2021). Yapay zekâ alanının hızla dönüşen yapısı, strateji için dinamik bir uygulama sürecini gerekli kılmaktadır. Ulusal Yapay Zekâ Stratejisi ile tüm paydaşların katılımıyla ülkemiz için ortaya çıkabilecek firsat, risk ve belirsizliklere hızlı cevap vermek mümkün olacaktır. Hayata geçirilecek tedbirler sayesinde yapay zekâ projelerinin etkin şekilde yürütülmesi, ülkemizin yapay zekâ ekosisteminin olgunluk seviyesinin yükseltilmesi ve küresel ölçekte değer üretilmesi hedeflenmektedir. 
TRT Akademi Dergisi'nin 13. sayısında “yapay zekâ” gibi stratejik bir konunun tema olarak seçilmesinden ve bu sayının editörü olmaktan dolayı onur duyduğumu ifade etmek isterim. Derginin hazırlık sürecinde, titiz çalışmalarından ötürü TRT Akademi Dergisi çalışan ve yöneticilerine kesintisiz destek ve iş birlikleri için teşekkür ediyorum. Bu sayımızın alan yazın başta olmak üzere uygulamacılara, iş insanlarına, öğrencilere ve yapay zekâya ilgi duyan herkese yararlı olmasını temenni ederim.

\section{Kaynakça}

Acemoğlu, D. \& Restrepo, P. (2020). Robots and Jobs: Evidence from US Labor Markets. Journal of Political Economy, 128(6), 2188-2244.

Bostrom, N. (2018). Süper Zekâ: Yapay Zekâ Uygulamaları, Tehlikeler ve Stratejiler, (Çev. Ferit Burak Aydar). İstanbul: Koç Üniversitesi Yayınları-184.

Ergen, M. (2019). What is Artificial Intelligence? Technical Considerations and Future Perception. The Anatolian Journal of Cardiology, 22(2), 5-7.

Howard, J. (2019). Artificial Intelligence: Implications for the Future of Work. American Journal of Industrial Medicine, 62(11), 917-926.

IFR - International Federation of Robotics. (2020). https://ifr.org/free-downloads/ (Erişim Tarihi: 01.09.2021).

İyigün, N. Ö. (2021). Yapay Zekâ ve Gelecek: İnsan ve Teknoloji Arasındaki İlişki. Içinde Yapay Zekâ: Güncel Yaklaşımlar ve Uygulamalar (Ed. N. Ö. İyigün \& M. K. Yılmaz). İstanbul: Beta Yayınları.

Kaya, İ., \& Engin, O. (2005). Kalite İyileştirme Sürecinde Yapay Zekâ Tekniklerinin Kullanımı. Pamukkale Üniversitesi Mühendislik Bilimleri Dergisi, 11(1), 103-114.

Köse, U. (2018). Are We Safe Enough in the Future of Artificial Intelligence? A Discussion on Machine Ethics and Artificial Intelligence Safety. Broad Research in Artificial Intelligence and Neuroscience, 9(2), 184-197.

Schmidt, E. (2021). Gazete Oksijen, https://gazeteoksijen.com/dunya/yapay-zekada-demokrasi-savasi/ (Erişim Tarihi: 04.09.2021)

Ulusal Yapay Zekâ Stratejisi. (2021). https://cbddo.gov.tr/SharedFolderServer/Genel/File/ TR-UlusalYZekaStratejisi2021-2025.pdf (Erişim Tarihi: 03.09.2021) 


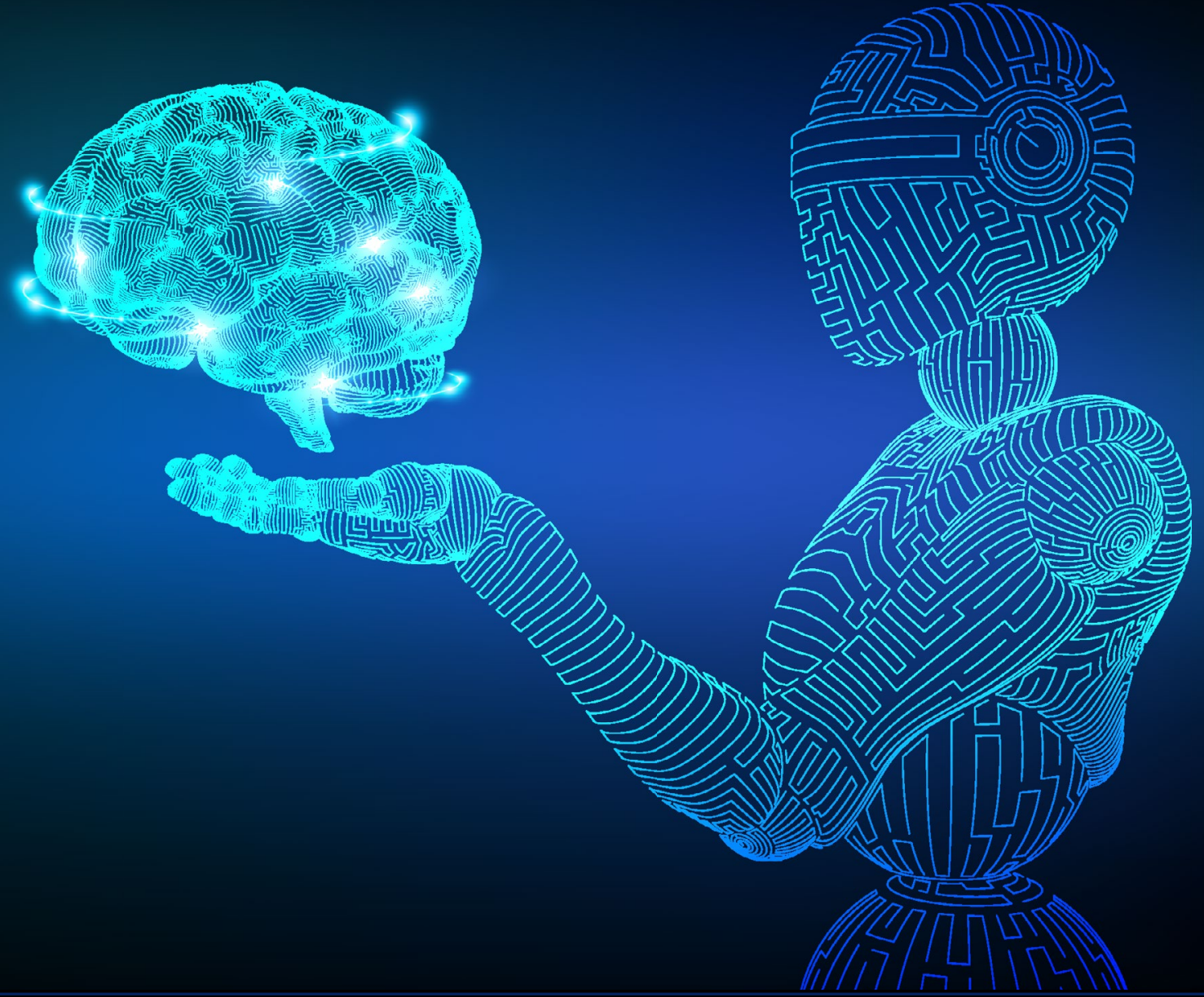

